\title{
Fog-induced variations in aerosol optical and physical properties over the Indo-Gangetic Basin and impact to aerosol radiative forcing
}

\author{
S. K. Das ${ }^{1}$, A. Jayaraman ${ }^{2}$, and A. Misra ${ }^{1}$ \\ ${ }^{1}$ Physical Research Laboratory, Ahmedabad, 380 009, India \\ ${ }^{2}$ National Atmospheric Research Laboratory, Gadanki, 517112, India
}

Received: 9 May 2007 - Revised: 4 March 2008 - Accepted: 13 March 2008 - Published: 11 June 2008

\begin{abstract}
A detailed study on the changes in aerosol physical and optical properties during fog events were made in December 2004 at Hissar $\left(29.13^{\circ} \mathrm{N}, 75.70^{\circ} \mathrm{E}\right)$, a city located in the Indo-Gangetic basin. The visible aerosol optical depth was relatively low (0.3) during the initial days, which, however, increased (0.86) as the month progressed. The increasing aerosol amount, the decreasing surface temperature and a higher relative humidity condition were found favoring the formation of fog. The fog event is also found to alter the aerosol size distribution. An increase in the number concentration of the nucleation mode (radius $<0.1 \mu \mathrm{m}$ ) particles, along with a decrease in the mode radius showed the formation of freshly nucleated aerosols. In the case of accumulation mode $(0.1 \mu \mathrm{m}<$ radius $<1.0 \mu \mathrm{m})$ an increase in the mode radius was observed showing the hygroscopic and coagulation growth of particles. The observed aerosol optical depth spectra are model fitted to infer the aerosol components which are further used to compute the aerosol radiative forcing. The top of the atmosphere forcing is found to increase during foggy days due to large backscattering of radiation back to space. It is also shown that during foggy days, as the day progresses the $\mathrm{RH}$ value decreases, which reduces the forcing value while the increasing solar elevation increases the forcing value. Thus the fog event which prolongs longer into the daytime has a stronger effect on the diurnally averaged aerosol radiative forcing than those events which are confined only to the early morning hours.
\end{abstract}

Keywords. Atmospheric composition and structure (Aerosols and particles; Pollution - urban and regional; Transmission and scattering of radiation)

Correspondence to: S. K. Das

(sanat@prl.res.in)

\section{Introduction}

Aerosols play an important role in the Earth's atmosphere system by interacting with the incoming solar radiation and the outgoing longwave radiation. Our present knowledge on the regional scale variation of aerosol properties is however not sufficient to fully incorporate the effects of aerosols in climate change studies. In order to fill-in the knowledge gap, there have been a large number of field campaigns conducted around the globe, such as Aerosol Characterization Experiment (ACE) (Bates et al., 2002), Tropospheric Aerosol Radiative Forcing Observational Experiment (TARFOX) (Russel et al., 1999), Smoke, Clouds, and RadiationBrazil (SCAR-B) (Nobre et al., 1998), Indian Ocean Experiment (INDOEX) (Ramanathan et al., 2001), etc. There have been consistent efforts over the Indian region to characterize the spatial and temporal variations of aerosols through campaigns realized under the Indian Middle Atmosphere Program (IMAP) during the mid eighties and early nineties (e.g. Jayaraman and Subbaraya, 1993) and lately under the Indian Space Research Organisation's Geosphere Biosphere Program (ISRO-GBP) (e.g. Subbaraya et al., 2000; Jayaraman et al., 2006). Within the Indian region, the Indo-Gangetic Basin (IGB), located in the northern part of India, is of particular importance as it is the highly aerosol loaded region and has the largest aerosol optical depth during both summer and winter seasons (Jethva et al., 2005). In this region the domestic energy consumption largely depends on biofuels (such as cow-dung cake, wood, straw and other agriculture wastes) in rural areas and mainly fossil fuels in urban areas. During winter, industrial urban locations like Kanpur and Delhi show high amounts of black carbon loading which has a large radiative forcing impact on climate (Tripathi et al., 2005; Ganguly et al., 2006).

In the Indo-Gangetic Basin (IGB), occurrence of fog during the winter season is a common feature. At high relative humidity conditions aerosols act as condensation nuclei,

Published by Copernicus Publications on behalf of the European Geosciences Union. 


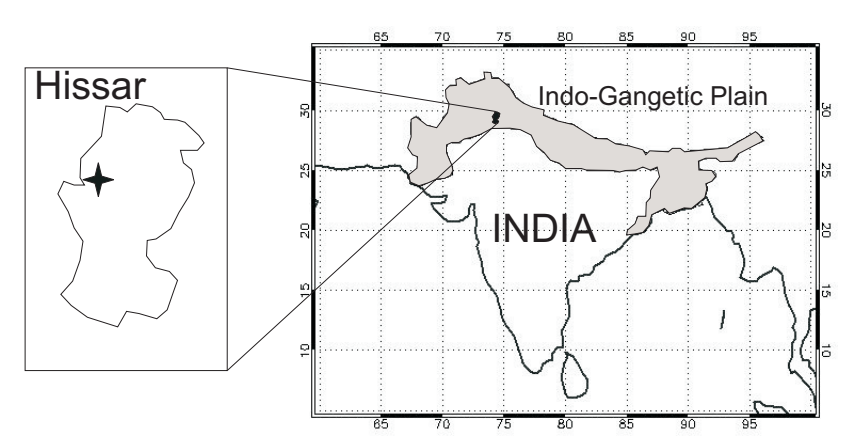

Fig. 1. Map showing the Indo-Gangetic Basin (IGB) and the observation site at $\operatorname{Hissar}\left(29.13^{\circ} \mathrm{N}, 75.70^{\circ} \mathrm{E}\right)$.

which help to produce the fog, which, in turn, can ultimately alter the properties of the aerosols (Pandis and Seinfeld, 1990). Fog, in general, starts occurring late at night and continues up to about the next day at noon. In this paper we study the aerosol properties and their changes during fog conditions in the IGB through a month long field campaign conducted at Hissar $\left(29.13^{\circ} \mathrm{N}, 75.70^{\circ} \mathrm{E}\right)$ (Fig. 1) in December 2004 as part of the ISRO-GBP Land Campaign-II. We also estimate the aerosol radiative forcing and its diurnal variation during the fog period and compare with that during clear sky conditions.

\section{Meteorological condition}

Meteorological parameters are the important tools to study changes in the aerosol properties due to the fog event. In our present work, we have divided all the data into three groups, namely, "prior to foggy days" (6, 8 and 11 December), "during foggy days" (12, 13 and 14 December) and "after the foggy days" (15, 17, 18 and 27 December) on the basis of three different conditions of meteorological parameters. The main important meteorological parameter which carries all the signatures of fog is relative humidity $(\mathrm{RH})$. Figure 2a shows the variation in RH during the observational period. Prior to 12 December no strong variation in RH was observed, but on the 12th, 13th and 14th, during the morning hours, $\mathrm{RH}$ was found to be very high, and significant diurnal variation was observed. On the 19 th and after the 21 st, almost everyday, $\mathrm{RH}$ showed a high value during the morning and decreased rapidly and even reached values below $25 \%$ during the afternoon hours. On the 22 nd the fog event continued over the entire day as the RH remained high throughout the day. On the 15, 17, 18 and 27 December no significant change in RH variation was observed during the whole day and no fog event was observed. These days are considered as "after the foggy days". Temperature and pressure values (Fig. $2 b-c$ ) also followed the same kind of variation as that of RH. During the foggy days both the surface pressure and temperature decreased. Prior to and after the foggy days these two parameters showed almost a similar variation. The wind in general was observed to come mainly from the NE direction (Fig. 2d). During the foggy days wind was in general calm during the forenoon (FN) period (Fig. 2e), which helped to retain the fog over a longer duration. During the afternoon (AN) the wind speed was found to be higher than the FN values, and also during the non-foggy days the wind speed was found to be higher. Also, it should be noted that the atmospheric boundary layer height undergoes both diurnal and day-to-day variation depending on the surface temperature variation. This variation induces a strong modulation in the surface aerosol amount, such that when the boundary layer height is low the surface aerosol amount is high and vice versa. This however does not greatly influence the total column concentration of aerosol and hence the columnar aerosol optical depth.

\section{Measurements}

During the campaign period, from 1 to 30 December, the spectral Aerosol Optical Depth (AOD) and the aerosol mass size distribution were measured at Hissar. The AOD was obtained by measuring the direct solar radiation intensity at the ground by a hand-held Sunphotometer, built in-house at the Physical Research Laboratory, Ahmedabad. The Sunphotometer consists of an interference filter, photodiode and necessary electronics (Acharya and Jayaraman, 1995). Direct solar-intensity was measured at seven wavelength bands by using optical interference filters, having maximum transmission centered around 400, 500, 668, 750, 875 and 1050-nm with corresponding full-width at half maximum (FWHM) of $18,13,9,10,12$ and $25-\mathrm{nm}$, respectively. The field of view of the Sunphotometer is kept at $6^{\circ}$ by using a front-end baffle. Observations were made during cloud-free conditions, from 08:30 to 16:30 local time, with typical half an hour interval between the measurements. Each observation consists of measurements taken successively for all the optical channels by changing the interference filters. While the absolute error in the AOD calculation is about 0.03 the relative error can reach up to a maximum of $15 \%$ due to instrumental error (due to bias and precision) and ignoring the contribution from "forward" scattering particularly during high aerosol condition and for low zenith angle observation (Jayaraman et al., 1998).

Aerosol mass concentration was measured using a 10stage Quartz Crystal Microbalance (QCM) cascade impactor (model PC-2, California Measurements Inc., USA) and the aerosol size distribution at the ground level was determined. The aerosols were collected in 10 stages of the impactor with $50 \%$ efficiency cut-off radii at 12.5, 6.25, 3.2, 1.6, 0.8, $0.4,0.2,0.1,0.05$ and $0.025 \mu \mathrm{m}$ from stage 1 to 10 , respectively. The air flow rate through the impactor was kept at $240 \mathrm{ml} / \mathrm{min}$. The typical sampling period was $60 \mathrm{~s}$ for each measurement. The maximum uncertainty in the measured 


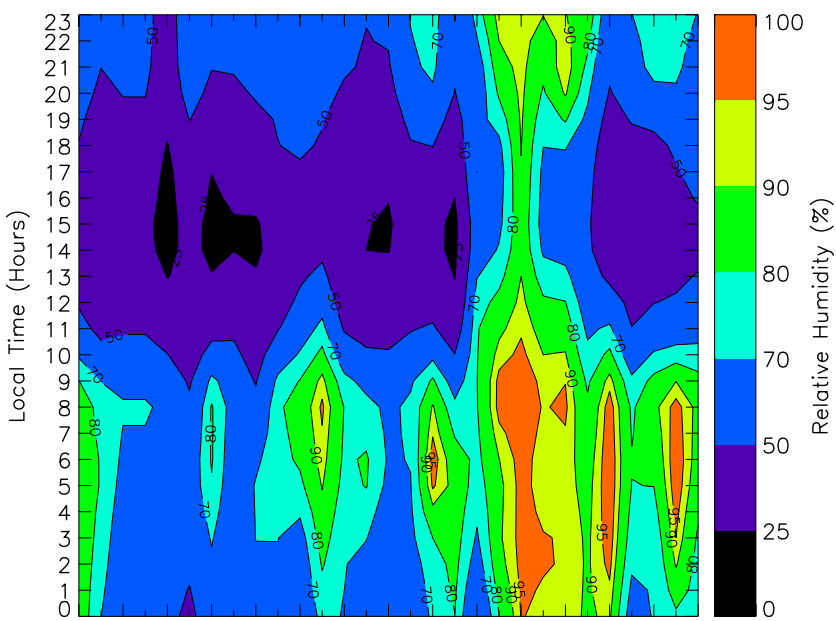

(a) $\begin{array}{lllllllllllllll}02 & 04 & 06 & 08 & 10 & 12 & 14 & 16 & 18 & 20 & 22 & 24 & 26 & 28 & 30\end{array}$
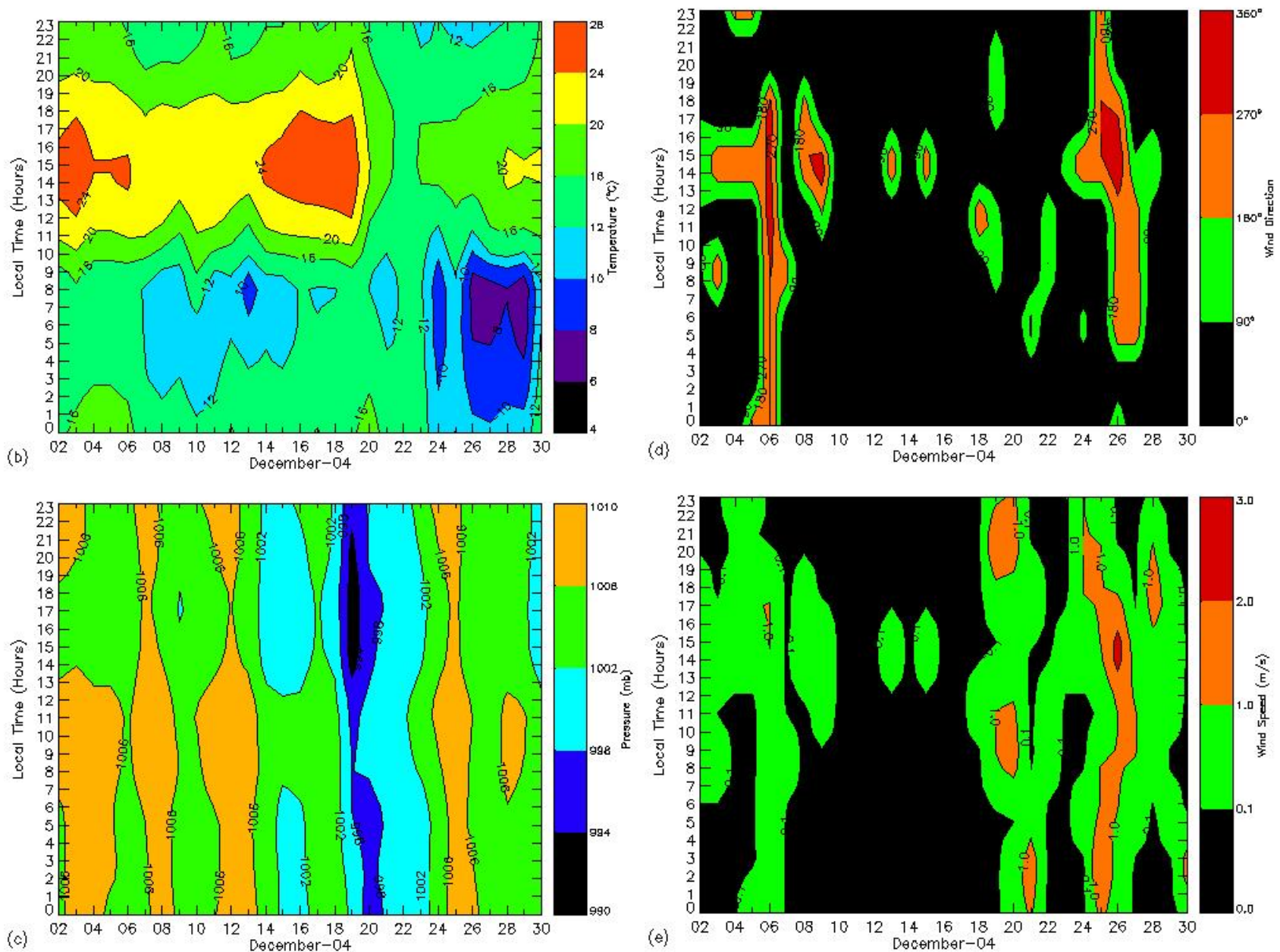

Fig. 2. Relative humidity, temperature, pressure, wind direction and speed observed at Hissar during the campaign period. Foggy periods are observed (Fig. 2a) on 12, 13, 14, 20 and 22, 26 and 29 December when the RH values are above $90 \%$ 

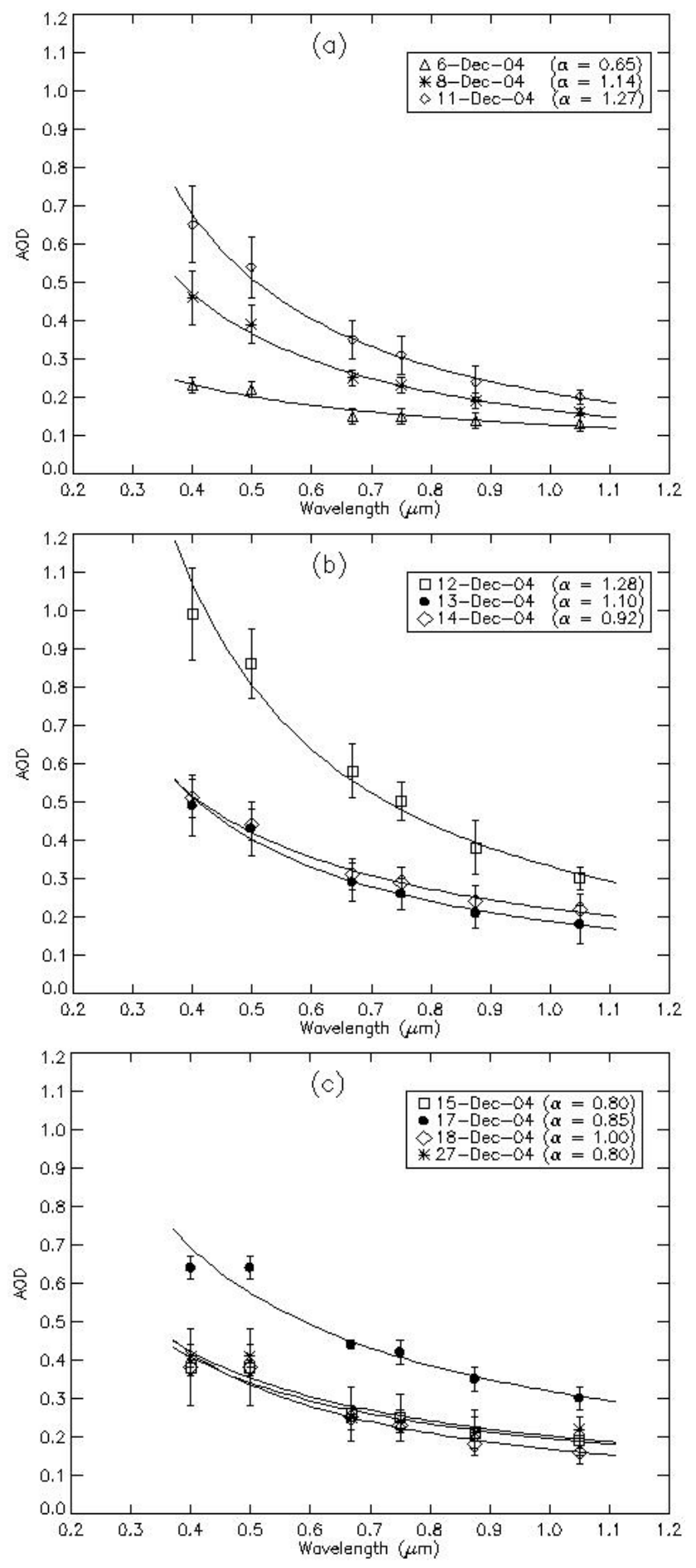

Fig. 3. Average aerosol optical depth (AOD) values obtained (a) prior to foggy days (6, 8 and 11 December 2006) (b) during foggy days (12, 13 and 14 December 2006, afternoon hours) and (c) after foggy days (15, 17, 18 and 27 December 2006). Measurements could not be made on other days due to cloudy sky conditions. Best fitted lines, drawn by a least-squares method, are also shown in the figure. mass for all ten stages of QCM is within 25\% (Jayaraman et al., 1998).

The QCM was operated from the terrace of the observatory building at a height of about $6 \mathrm{~m}$. The air inlet was installed vertically to minimize the loss of aerosol particles within the inlet tube. The relative temperature change of the crystals during each sampling period of $1 \mathrm{~min}$ is too small and can be neglected. The QCM observations were made during the day, with an interval of about one hour from 08:00-17:00 local time except for days when the $\mathrm{RH}$ was above $75 \%$, as well as during dense fog conditions to avoid any damage to the QCM crystals. The QCM data is also compared with the aerosol mass independently obtained using a High Volume Sampler (HVS), which had a maximum cut-off radius of $10 \mu \mathrm{m}$.

\section{Results and discussion}

\subsection{AOD over Hissar}

Figure 3 shows the AOD spectra obtained in the wavelength range from $400 \mathrm{~nm}$ to $1050 \mathrm{~nm}$ from 6 December to $30 \mathrm{De}-$ cember 2004. Only 10 days of observations could be made, as other days were either cloudy or influenced by heavy fog conditions. Prior to the occurrence of foggy days over Hissar, daily AOD data are available for 3 days. Among the "prior to foggy days" period, 6 December has the lowest AOD value $(0.22)$, which gradually increased on later days. On $11 \mathrm{De}-$ cember, prior to the start of the foggy period, the AOD at 500-nm showed a maximum value of 0.54 (Fig. 3a). During foggy days, AOD observations at FN hours were not possible due to poor visibility. After fog has dissipated, AOD observations could be made in the AN hours under clear sky conditions. In general, higher AOD values were observed during foggy days. On 12 December the highest AOD value of 0.99 has been observed at 500-nm (Fig. 3b). The values were however less on 13 and 14 December. 15 December was a cleaner day, with comparatively less AOD values (Fig. 3c), indicating scavenging of particles during the foggy days.

Delhi $\left(28.63^{\circ} \mathrm{N}, 77.17^{\circ} \mathrm{E}\right)$, which is $200 \mathrm{~km}$ southeast of Hissar, is another greatly polluted urban region in the IGB. The monthly averaged AOD at $500 \mathrm{~nm}$ during December 2004 was reported as $0.91 \pm 0.48$ (Ganguly et al., 2006), whereas in Hissar it was $0.46 \pm 0.18$. At Kanpur $\left(23.43^{\circ} \mathrm{N}\right.$, $\left.80.33^{\circ} \mathrm{E}\right)$, another major industrial region in the IGB, situated $350 \mathrm{~km}$ further east from Delhi, the monthly mean AOD value of $0.77 \pm 0.29$ was reported for the same period (Tripathi et al., 2005).

Angstrom exponent $\alpha$, the slope of the linear correlation between wavelength (in $\mu \mathrm{m}$ ) and AOD in logarithmic scale is an important parameter which provides indirect information on the aerosol size distribution. Prior to the foggy day period, $\alpha$ (computed for the entire wavelength range from 0.40 to $1.050 \mu \mathrm{m}$ ) was found to be higher than compared to that for the foggy days. A decrease in the $\alpha$ value indicates 
Table 1. Aerosol mass concentration $(\mathrm{m})$, number concentration $(\mathrm{N})$, mode radius $\left(r_{m}\right)$ and width $(\sigma)$ of the fitted lognormal distributions for the nucleation mode $(r<0.1 \mu \mathrm{m})$, accumulation mode $(0.1<r<1.0 \mu \mathrm{m})$, and the coarse mode $(r>1.0 \mu \mathrm{m})$.

\begin{tabular}{|c|c|c|c|c|c|c|c|c|c|c|c|c|}
\hline \multirow{2}{*}{ Days } & \multicolumn{4}{|c|}{ Nucleation mode } & \multicolumn{4}{|c|}{ Accumulation mode } & \multicolumn{4}{|c|}{ Coarse mode } \\
\hline & $\begin{array}{c}\mathrm{M} \\
\left(\mu \mathrm{g} / \mathrm{m}^{3}\right)\end{array}$ & $\begin{array}{c}\mathrm{N} \\
(\text { per cc) }\end{array}$ & $\begin{array}{c}r_{m} \\
(\mu \mathrm{m})\end{array}$ & $\begin{array}{c}\sigma \\
(\mu \mathrm{m})\end{array}$ & $\begin{array}{c}\mathrm{M} \\
\left(\mu \mathrm{g} / \mathrm{m}^{3}\right)\end{array}$ & $\begin{array}{c}\mathrm{N} \\
(\text { per cc) }\end{array}$ & $\begin{array}{c}r_{m} \\
(\mu \mathrm{m})\end{array}$ & $\begin{array}{c}\sigma \\
(\mu \mathrm{m})\end{array}$ & $\begin{array}{c}\mathrm{M} \\
\left(\mu \mathrm{g} / \mathrm{m}^{3}\right)\end{array}$ & $\begin{array}{c}\mathrm{N} \\
(\text { per cc) }\end{array}$ & $\begin{array}{c}r_{m} \\
(\mu \mathrm{m})\end{array}$ & $\begin{array}{c}\sigma \\
(\mu \mathrm{m})\end{array}$ \\
\hline Before Fog & 9.0 & 45000 & 0.030 & 1.28 & 37.1 & 350 & 0.10 & 1.31 & 57.6 & 0.018 & 2.8 & 1.16 \\
\hline Foggy Days & 26.0 & 72000 & 0.025 & 1.35 & 107.3 & 800 & 0.16 & 1.23 & 71.2 & 0.18 & 1.8 & 1.23 \\
\hline After Fog & 23.4 & 40000 & 0.029 & 1.25 & 62.6 & 470 & 0.13 & 1.28 & 48.9 & 0.15 & 1.7 & 1.25 \\
\hline
\end{tabular}

the relative increase in the amount of bigger particles, and in the present case the hygroscopic growth of particles during the foggy period. It should be noted that even after the foggy days the $\alpha$ value continued to remain low, indicating the continued presence of wet aerosols in the atmosphere.

\subsection{Aerosol mass concentration over Hissar}

The role of aerosols in climate change also depends, apart from their optical and chemical properties, on their size distribution, as it controls both the vertical and horizontal dispersal of particles. The aerosol mass concentration at Hissar, prior to foggy days was comparatively low, about $100 \mu \mathrm{g} / \mathrm{m}^{3}$ (with the exception of 4 December) with respect to the foggy and after foggy days (Fig. 4). During foggy days mass concentrations were found in general to be high. At higher RH there is a possibility that the particles become coated with an aqueous solution of any soluble constituents (Lubin et al., 2002). After foggy days the aerosol mass concentration reduced but did not reach the value that was obtained prior to the foggy days. The observed reduction in the aerosol mass concentration is mainly attributed to the scavenging of particles during the foggy days.

\subsection{Aerosol number distribution}

The measured aerosol mass concentration is converted into an aerosol number distribution in the size region 0.025$12.5 \mu \mathrm{m}$ for the three periods, viz., before foggy days (28 December), during foggy days $(12-14,20,29$ December) and after foggy days (15-19, 21, 23-28 and 30 December) by using appropriate densities for the particles, taking into account the measured $\mathrm{RH}$ value. The aerosol number distributions for the three periods are shown in Fig. 5a-c. The vertical bars correspond to the standard deviation of the mean value, representing the variation in the number density values within a day. The observed data is fitted best by a sum of three individual log-normal curves for the three modes, viz., nucleation mode $(r<0.1 \mu \mathrm{m})$, accumulation mode $(0.1<r<1.0 \mu \mathrm{m})$, and the coarse mode $(r>1.0 \mu \mathrm{m})$, with varying mode radius $\left(r_{m}\right)$ and standard deviation $(\sigma)$.

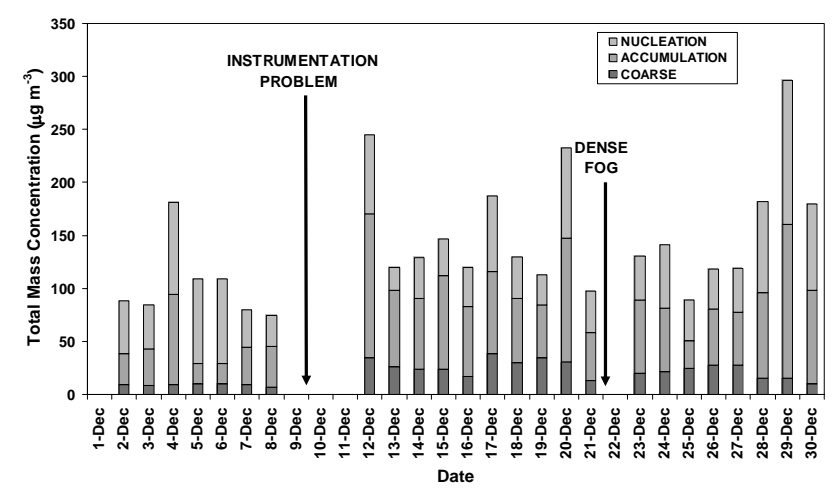

Fig. 4. Average aerosol mass concentration obtained during the campaign period. The total mass values are averaged for nucleation (particles radii $<0.1 \mu \mathrm{m}$ ), accumulation $(0.1-1.0 \mu \mathrm{m})$ and coarse $(>1.0 \mu \mathrm{m})$ modes. Observations were made only for $\mathrm{RH}<75 \%$. No measurements were made during dense fog condition.

Table 1 gives the aerosol number concentration $\mathrm{N}$ in $\mathrm{cm}^{-3}$, $r_{m}$ and $\sigma$ for the three modes.

During foggy days an increase in aerosol mass concentration is found in all three modes while the increase is larger in the nucleation and accumulation modes. The nucleation and accumulation mode particles are mainly water soluble or soot particles. During foggy periods the water soluble particles adsorb water and become larger while the soot particles can become coated with either liquid water or an aqueous solution of any soluble constituents (Lubin et al., 2002), resulting in an increase in their mass. Our observation also shows that there was a large increase in the number concentration in the nucleation mode particles. It is interesting to note that there is a reduction in the mode radius value (which could be determined with an accuracy of about 0.002 or better for all modes) of the nucleation mode particles from 0.03 to $0.025 \mu \mathrm{m}$ during foggy days, which shows the addition of freshly nucleated particles, while in the accumulation mode the mode radius shifts to larger side, from 0.1 to $0.16 \mu \mathrm{m}$, showing the growth of the particles. Thus, during foggy days the increase in nucleation mode particles is mainly due to the addition of freshly nucleated particles while in the 

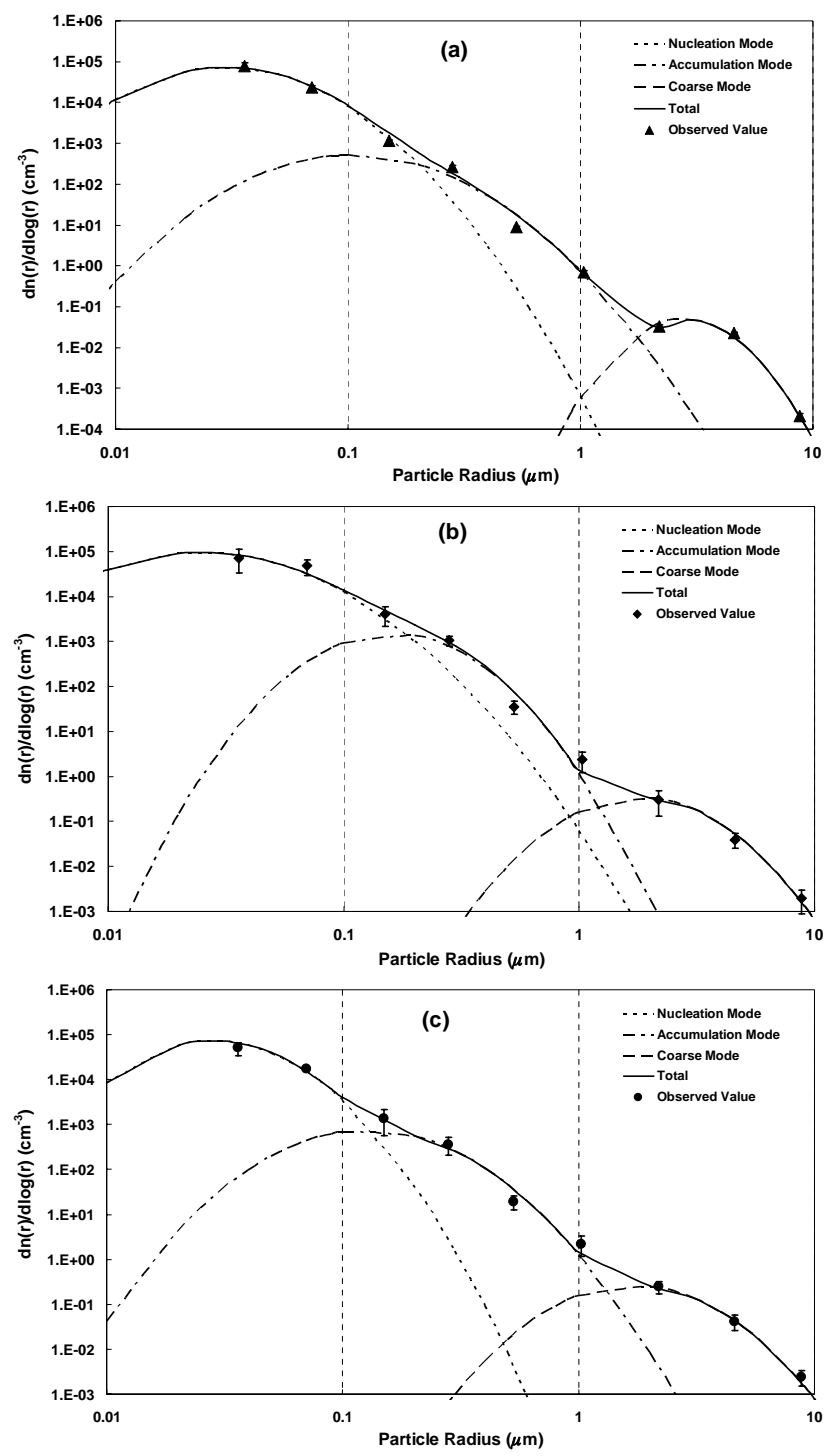

Fig. 5. Mean aerosol number distribution (a) prior to foggy days (mean of 2-8 December 2004) (b) during foggy days (mean of 1214, 20 and 29 December 2004) and (c) after foggy days (mean of 15-19, 21, 23-28 and 30 December 2004). The observed values are fitted with log-normal curves individually for the three modes, viz, nucleation, accumulation and coarse modes. The sum of the three modes is also shown.

accumulation mode, the observed increase in mass is mainly due to the hygroscopic and coagulation growth of particles. However, after the foggy days there was a decrease observed both in the mass and number concentration of the particles in all the three modes and the decrease was stronger in the coarse mode, indicating the scavenging of particles during the foggy days, which was however more efficient for the coarse particles.
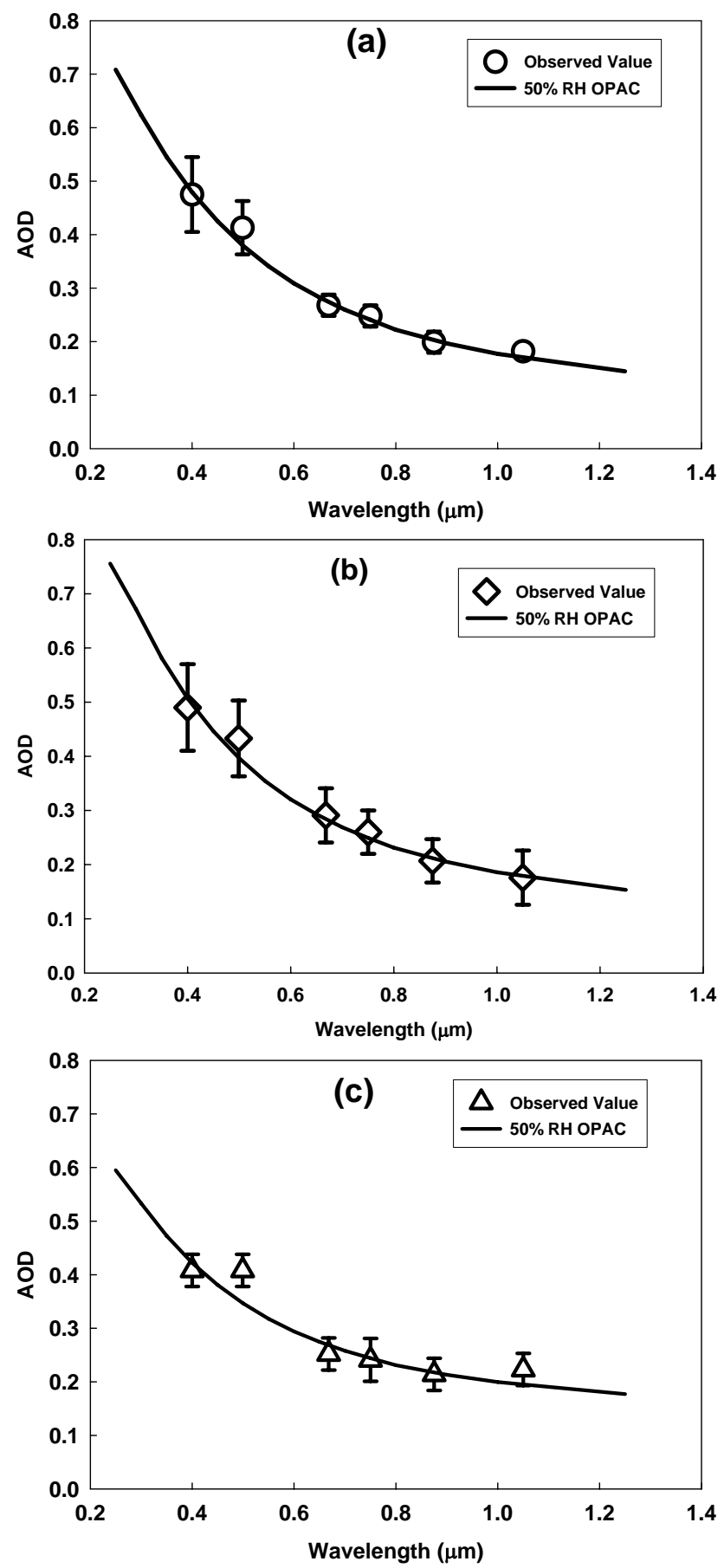

Fig. 6. Average aerosol optical depth spectra obtained on 8, 13 and 27 December are fitted with OPAC model values.

\subsection{Estimation of aerosol components}

To estimate chemical compositions of aerosol, the OPAC (Optical Properties of Aerosols and Clouds) model (Hess et al., 1998) is used to best fit the observed aerosol optical depth spectra. This will help in understanding the changes 


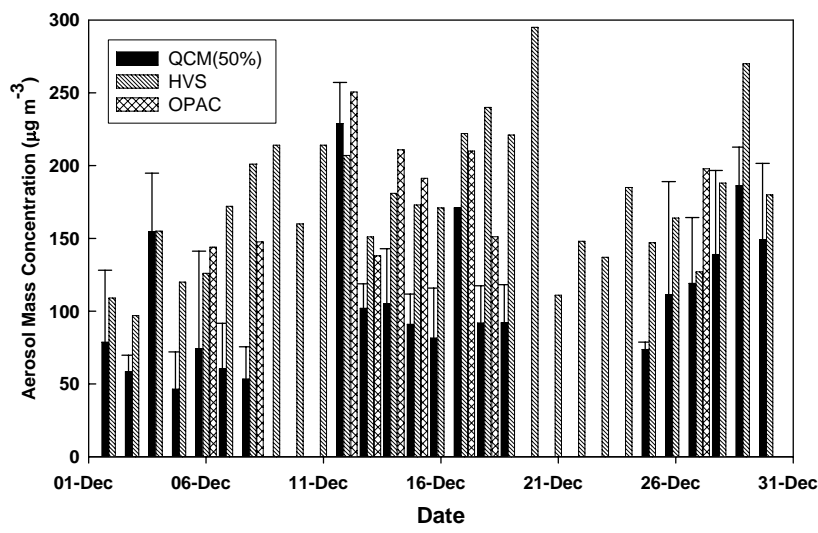

Fig. 7. QCM mass concentration compared with the estimated mass concentration using OPAC mode, and High Volume Sampler (HVS) data.

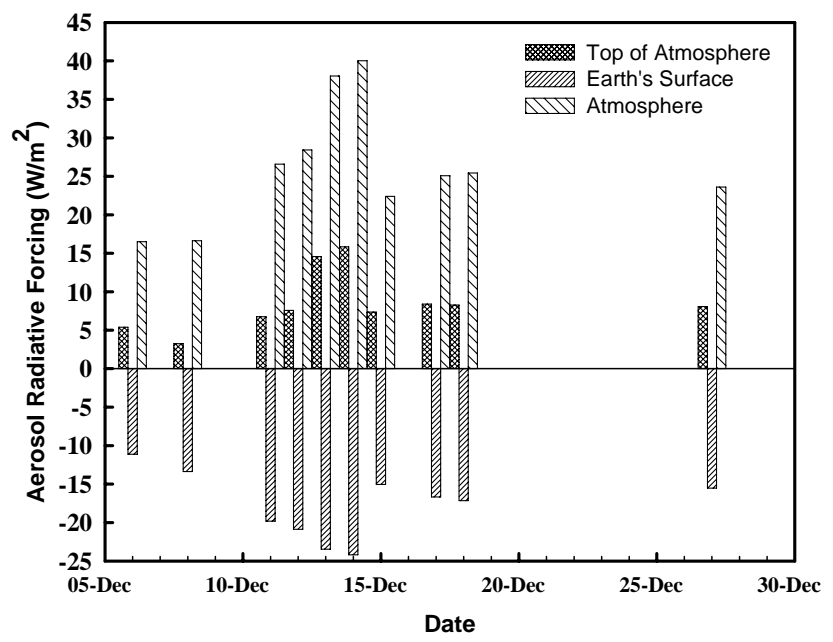

Fig. 8. Daily averaged aerosol radiative forcing over Hissar for those days when aerosol optical depth data are available.

in aerosol physical and optical properties, such as aerosol scattering, absorption and extinction coefficients and single scattering albedo $(\omega)$ during different RH conditions. When RH increases water soluble particles, such as sea salt and sulfates will grow and when $\mathrm{RH}$ exceeds $80 \%$, the aerosol components can be modified by both particle growth and transformation to an aqueous solution, which, in turn, can affect the refractive index of the components (Lubin et al., 2002).

For all days, the AOD observed during the afternoon hours, when the RH value is less than $50 \%$ are compared with OPAC produced AOD (Fig. 6) and the relative abundances of aerosol components, such as water soluble (WS), insoluble (IS), soot (SO) and mineral dust (MD) are estimated. The most dominating components are found to be WS and SO. The soot particle concentration is found between the continental average and the urban aerosol types, as defined by Hess et al. (1998). In Table 2 aerosol components for three
Table 2. Aerosol components, viz., Soot (SO), Water Soluble (WS), Water Insoluble (IS) and Mineral Dust (MD) are estimated from OPAC model fitting of the observed aerosol optical depth (AOD) spectra. The Angstrom Parameter $(\alpha)$ estimated for the observed as well as the fitted AOD spectra are compared.

\begin{tabular}{lcccccc}
\hline \multirow{2}{*}{ Date } & \multicolumn{3}{c}{$\begin{array}{c}\text { Aerosol components } \\
\text { (particles/cc) }\end{array}$} & \multicolumn{3}{c}{ Angstrom } \\
& SO & WS & IS & MD & Observed & OPAC \\
\hline 8 December & 24000 & 18000 & 2.0 & 2.0 & 1.14 & 1.1 \\
13 December & 60000 & 27000 & 1.3 & 3.0 & 1.09 & 1.1 \\
27 December & 55000 & 12000 & 1.5 & 8.5 & 0.80 & 0.83 \\
\hline
\end{tabular}

different days representing prior to foggy days, during foggy days and after the foggy days are given and the corresponding angstrom parameter, $\alpha$, are compared. During foggy days both soot and WS particle concentrations have increased and after foggy days though their number concentrations have decreased, they have not reached the values that were observed prior to the foggy days.

Aerosol mass concentrations, measured by QCM and HVS, are compared with the OPAC estimated aerosol mass concentration (Fig. 7). While HVS gives the total mass concentration of particles collected on quartz filter paper for a whole day $(24 \mathrm{~h})$ and used further for chemical analysis (Ramachandran et al., 2006) the QCM measurements were limited to only daytime, and data corresponding to $50 \% \mathrm{RH}$ or less are only considered. With increasing RH the WS component will undergo a major change in its size distribution. Also, the aerosol components can mix internally and externally with other components and hence the relative contribution of different components to the total aerosol loading can change after the foggy period. Therefore, on foggy days the AOD spectra obtained during the afternoon hours are only considered (after the fog has dissipated) and fitted with OPAC model. Prior to foggy days, the aerosol single scattering albedo (SSA) at $500 \mu \mathrm{m}$, determined by OPAC fitting the observed AOD spectra SSA was $0.83 \pm 0.03$ at $50 \% \mathrm{RH}$ while during foggy days (in the afternoon hours) the SSA value was $0.72 \pm 0.08$ at RH $50 \%$, which, however, increases to 0.82 at $70 \%$. The very low SSA value obtained after the foggy period was mainly due to the scavenging of scattering particles (which are also hygroscopic), such as sulfate and dust while the submicron soot particles, which are hygrophobic and contribute to the absorption, were less scavenged.

\subsection{Aerosol radiative forcing}

Aerosol radiative forcing (ARF) is calculated for the wavelength range $0.28-40 \mu \mathrm{m}$ using the Santa Barbara DISORT Aerosol Radiative Transfer (SBDART) model (Ricchiazzi et al., 1998) at the top of the atmosphere (TOA), within the 

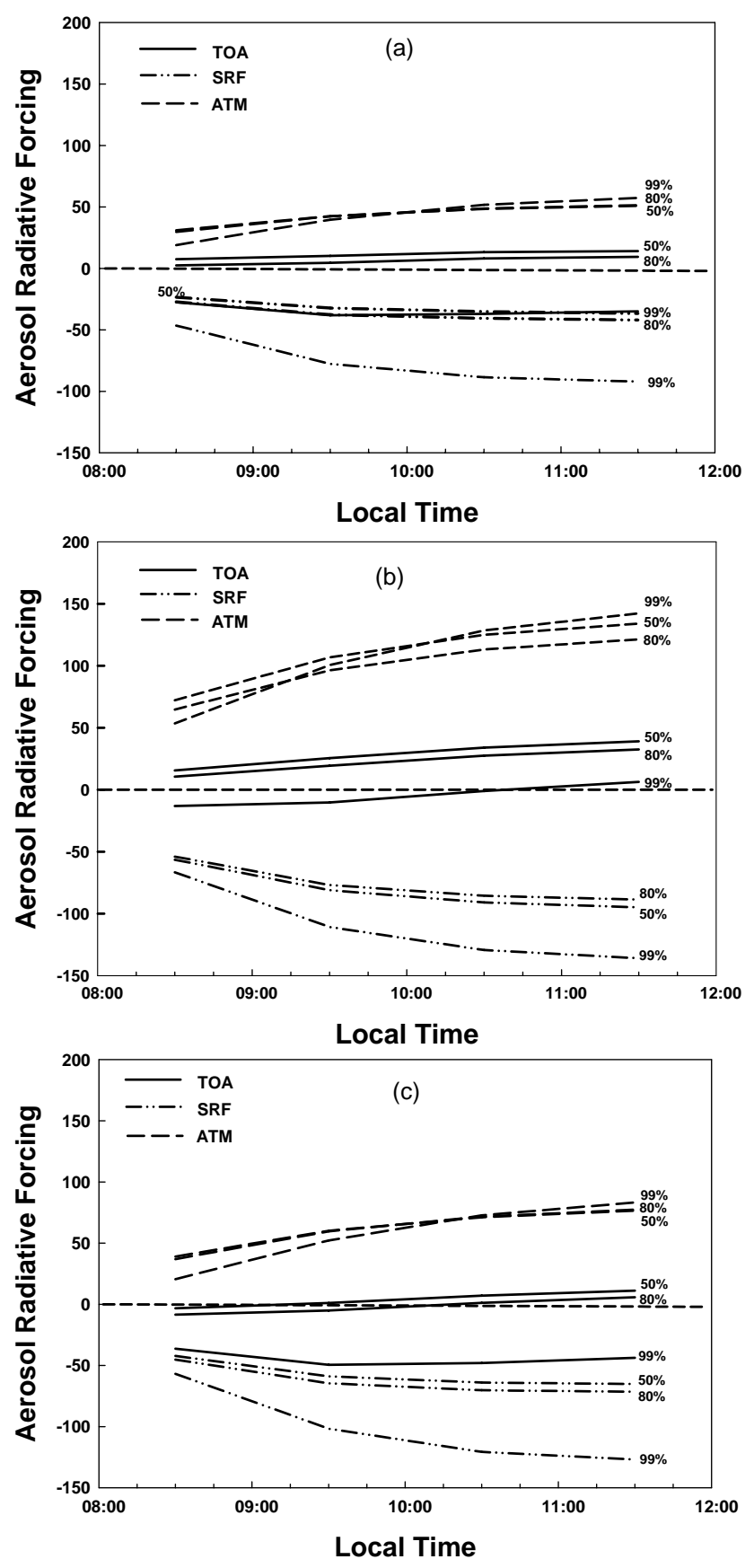

Fig. 9. Aerosol radiative forcing for $99 \%, 80 \%$ and $50 \% \mathrm{RH}$ values, at the top of the atmosphere (TOA), at the surface (SRF) and within the atmosphere (ATM) for (a) "before fog" days, 8 December (b) during foggy day, 13 December and (c) after foggy days, 17 December.

atmosphere and at the surface. The ARF values are estimated by running the radiative transfer code for an assumed aerosol free tropical atmosphere and with the specified aerosol components derived by model fitting the observed AOD spec- tra. Figure 8 shows the diurnally averaged ARF values for $50 \%$ RH computed for the campaign days when AOD values are available. Prior to the foggy days the ARF values are comparatively small with surface forcing in the range of $-10 \mathrm{~W} \mathrm{~m}^{-2}$, and the TOA forcing in the range of $5 \mathrm{~W} \mathrm{~m}^{-2}$, leading to an atmospheric forcing (difference between surface and the TOA forcings) of about $15 \mathrm{~W} \mathrm{~m}^{-2}$. However, during the foggy days $(12,13,14$ December) there is a large increase in ARF values with surface forcing in the range of -20 to $-25 \mathrm{~W} \mathrm{~m}^{-2}$ and TOA forcing in the range of 5 to $15 \mathrm{~W} \mathrm{~m}^{-2}$, and large atmospheric forcing in the range of 25 to $40 \mathrm{~W} \mathrm{~m}^{-2}$. The large forcing values are mainly due to the increase in the aerosol number concentration and size during the foggy days, as well as due to the relative increase in the abundance of absorbing particles due to poor ventilation. After the foggy days there is a reduction in the ARF values (Fig. 8) though they remained higher than the values obtained prior to the foggy days.

In order to study the effect of fog on the radiative forcing, the ARF values are computed on an hourly basis, taking into account the solar zenith angle variation, independently for the aerosol components obtained for the "before fog" days, foggy days and after the foggy days. The individual aerosol components estimated for the $50 \% \mathrm{RH}$ values are allowed to undergo changes for the RH values of $80 \%$ and $99 \%$ according to the OPAC model, and the new optical properties are used further to estimate the diurnal variation in the ARF values. While for low RH values the dependence on aerosol optical properties on the change in $\mathrm{RH}$ values can be neglected (more true for shorter wavelengths); at higher RH values even small changes in RH can cause large variations in the aerosol optical properties.

It is known that radiative forcing depends on the solar zenith angle. On foggy days, however, the RH value also undergoes large diurnal variation from a morning high of more than $90 \%$ to an afternoon low of about $50 \%$ or less. Figure $9 \mathrm{a}-\mathrm{c}$ show the results of changes in the ARF values for both solar zenith angle and RH variations for the aerosol components estimated independently for the "before fog" days, foggy days and after the foggy days. One of the main findings is that as the RH values become very high (shown for 99\%) the TOA forcing becomes negative due to large backscattering of radiation to space as a consequence of changing SSA. Thus there is a corresponding decrease in the atmospheric forcing. Also, the nature of the diurnal variation depends on the relative abundances of different aerosol components, and in case of "foggy days" the diurnal variation (Fig. 9b) is found to be larger, as it is also evident from the low SSA values and high AOD values. Also, on foggy days, as the day progresses the decreasing RH value reduces the forcing value while the decreasing solar zenith angle increases the forcing values. Thus the effect of decreasing RH and the solar zenith angle have the opposite effect on the ARF, while the effect of the latter is found to be larger. 


\section{Conclusions}

Under the ISRO-GBP land campaign II a detailed study on the aerosol physical and optical properties was made during December 2004 at Hissar, a city located in the Indo-Gangetic basin. The location and the period are also conducive for the occurrence of fog. During the campaign period two major fog episodes were observed. The visible aerosol optical depth was relatively low (0.3) during the initial days, which, however, increased as the month progressed. The increasing aerosol amount, the decreasing surface temperature and a higher relative humidity condition were found favoring the formation of fog. However, immediately after the fog episode a systematic change in the aerosol size distribution was observed. The measured aerosol size distribution is fitted with three log-normal curves for the nucleation mode $(r<0.1 \mu \mathrm{m})$, accumulation mode $(0.1<r<1.0 \mu \mathrm{m})$, and the coarse mode $(r>1.0 \mu \mathrm{m})$. The fog event was found to alter the three modes in three different ways (Table 1). In case of the nucleation mode, an increase in number concentration and a decrease in mode radius (from 0.03 to $0.025 \mu \mathrm{m}$ ) were observed, showing the formation of freshly nucleated aerosols. In the case of accumulation mode an increase in the mode radius (from 0.1 to $0.16 \mu \mathrm{m}$ ) was observed, showing the hygroscopic and coagulation growth of particles, while for the coarse mode a large increase in mass concentration and an increase in the standard deviation were observed, showing a substantial increase in the amount of coarse particles (contributed from the accumulation mode) while a decrease observed in their mode radius (from 2.8 to $1.8 \mu \mathrm{m}$ ) shows the gravitational settling of bigger particles.

Aerosol radiative forcing (ARF) calculated using the SBDART model shows that the diurnally averaged ARF values prior to the foggy days were comparatively small while during the foggy days there was a large increase in their values, with surface forcing in the range of -20 to $-25 \mathrm{~W} \mathrm{~m}^{-2}$, TOA forcing in the range of 5 to $15 \mathrm{~W} \mathrm{~m}^{-2}$ and atmospheric forcing in the range of 25 to $40 \mathrm{~W} \mathrm{~m}^{-2}$. The large forcing values were mainly due to the increase in the aerosol number concentration during the foggy days, as well as due to the relative increase in the abundance of absorbing particles. After the foggy days a reduction in the ARF values was obtained. In order to study the effect of fog on the radiative forcing, the ARF values were also computed on an hourly basis using the aerosol components for the 50\% RH values but were allowed to undergo changes for RH values of $80 \%$ and $99 \%$ according to the OPAC model. One of the main findings is that as the RH value becomes very large the TOA forcing becomes negative due to large backscattering of radiation to space. This reduces the atmospheric forcing. Also, the nature of the diurnal variation depends on the relative abundances of different aerosol components. It is shown that during foggy days, as the day progresses the RH value decreases, which reduces the forcing value while the decreasing solar zenith angle increases the forcing value. The effect of decreasing
$\mathrm{RH}$ and the increasing solar zenith angle have the opposite effect on the ARF, but the effect of solar zenith angle variation influences the ARF more strongly. Thus the fog event which extends longer into the daytime hour has a stronger effect on the radiative forcing than those events which are confined to only the early morning hours.

Acknowledgements. The authors would like to acknowledge the ISRO-GBP Program office for funding the project. We are grateful to the Haryana State Remote Sensing Application Centre (HARSAC), Hissar for extending their valuable support and institute resources for carrying out the experiments in their premises.

Topical Editor F. D'Andrea thanks two anonymous referees for their help in evaluating this paper.

\section{References}

Acharya, R. Y. B. and Jayaraman, A.: Sun-photometry using photodiode open circuit voltage measurements, Rev. Sci. Instr., 66, 4087-4090, 1995.

Bates, T. S., Coffman, D. J., Covert. D. S., and Quinn, P. K.: Regional marine boundary layer aerosol distributions in the India, Atlantic, and Pacific Oceans: A comparison of INDOEX measurements with ACE-1, ACE-2, and Aerosols99, J. Geophys. Res., 107(D19), 8026, doi:10.1029/2001JD001174, 2002.

Ganguly, D., Jayaraman, A., Rajesh, T. A., and Gadhavi, H.: Wintertime aerosol properties during foggy and nonfoggy days over urban center Delhi and their impclications for shortwave radiative forcing, J. Geophys. Res., 111, D15217, doi:10.1029/2005JD007029, 2006.

Jayaraman, A. and Subbaraya, B. H.: In situ measurements of aerosol extinction profiles and their spectral dependencies at tropospheric levels, Tellus B, 45, 473-478, 1993.

Jayaraman, A., Lubin, D., Ramachandran, S., and Ramanathan, V.: Direct observations of aerosol radiative forcing over the tropical Indian 9191Ocean during the January-February 1996 preINDOEX cruise, J. Geophys. Res., 103, 13 827-13 836, 1998.

Jayaraman, A., Gadhavi, H., Ganguly, D., Misra, A., Ramachandran, S., and Rajesh, T. A.: Spatial variations in aerosol characteristics and regional radiative forcing over India: Measurements and modelling of 2004 road campaign experiment, Atmos. Environ., 40, 6504-6515, 2006.

Jethva, H., Satheesh, S. K., and Srinivasan, J.: Seasonal variability of aerosols over the Indo-Gangetic basin, J. Geophys. Res., 110, D21204, doi:10.1029/2005JD005938, 2005.

Hess, M., Koepke, P., and Schult, I.: Optical Properties of Aerosols and Clouds: the shoftware package OPAC, B. Am. Meteorol. Soc., 79, 831-844, 1998.

Lubin, D., Satheesh, S. K., McFarquar, G., and Heymsfeild, A. J.: Longwave radiative forcing of Indian Ocean tropospheric aerosol, J. Geophys. Res., 107(D19), 8004, doi:10.1029/2001JD001183, 2002.

Nobre, C. A., Mottes, L. F., Dereczynski, C. P., Tarasova, T. A., and Trosnikov, I. V.: Overview of atmospheric conditions during Smokes, Clouds and Radiation-Brazil (SCAR-B) field experiment, J. Geophys. Res., 103, 31 809-31 820, 1998.

Pandis, S. N. and Seinfield, J. H.: The smog-fog-smog cycle and acid deposition, J. Geophys. Res., 95, 18 489-18 500, 1990. 
Ramachandran, S., Rengarajan, R., Jayaraman, A., Sarin, M. M., and Das, S. K.: Aerosol radiative forcing during clear, hazy and foggy conditions over a continental polluted location in north India, J. Geophys. Res., 111, D20214, doi:10.1029/2006JD007142, 2006.

Ramanathan, V., Crutzen, P. J., Lelieveld, J., Mitra, A. P., Althausen, D., Anderson, J., Andreae, M. O., Cantrell, W., Cass, G. R., Chung, C. E., Clarke, A. D., Coakley, J. A., Collins, W. D., Conant, W. C., Dulac, F., Heintzenberg, J., Heymsfield, A. J., Holben, B., Howell, S., Hudson, J., Jayaraman, A., Kiehl, J. T., Krishnamurti, T. N., Lubin, D., McFarquhar, G., Novakov, T., Ogren, J. A., Podgorny, I. A., Prather, K., Priestley, K., Prospero, J. M., Quinn, P. K., Rajeev, K., Rasch, P., Rupert, S., Sadourny, R., Satheesh, S. K., Shaw, G. E., Sheridan, P., and Valero, F. P. J.: Indian Ocean Experiment: An integrated analysis of climate forcing and effects of the great Indo-Asian haze, J. Geophys. Res., 106, 28 371-28 398, 2001.
Ricchiazzi, P., Yang, S., Gautier, C., and Sowle, D.: SBDART: A research and teaching software tool for plane-parallel radiative transfer in the earth's atmosphere, B. Am. Meteorol. Soc., 79, 2101-2114, 1998.

Russel, P. B., Hobbs, P. V., and Stowe, L. L.: Aerosol properties and radiative effect in the United states east coast haze plume: An overview of the Tropospheric Aerosol Radiative Forcing Observational Experiments (TARFOX), J. Geophys. Res., 104, 22132222, 1999.

Subbaraya, B. H., Jayaraman, A., Krishnamoorthy, K., and Mohan, M.: Atmospheric aerosol studies under ISRO's Geosphere Biosphere programs, J. Ind. Geophys. Union, 4, 77-90, 2000.

Tripathi, S. N., Dey, S., Tare, V., and Sathees, S. K.: Aerosol black carbon radiative forcing at an industrial city in northern India, Geophys. Res. Lett., 32, L08802, doi:10.1029/2005GL022515, 2005. 